\title{
PELATIHAN KESELAMATAN DAN KESEHATAN KERJA (K3) PERTANIAN DI DESA ANTAPAN, KECAMATAN BATURITI, KABUPATEN TABANAN
}

\author{
Made Kurnia Widiastuti Giri \\ Universitas Pendidikan Ganesha \\ Email: widiastutikurnia@yahoo.com
}

\begin{abstract}
Abstrak
Petani merupakan kelompok kerja terbesar di Indonesia. Pertanian dan perkebunan dapat dianggap sebagai satu masyarakat tertutup, sehingga usaha-usaha kesehatan pun harus disesuaikan dengan sifat-sifat masyarakat demikian, dalam arti menyelenggarakan sendiri dan untuk kebutuhan sendiri. Perilaku K3 yang tepat dalam penggunaan pestisida sangat penting sebagai upaya pencegahan keracunan, sehingga perilaku K3 petani pengguna pestisida perlu disosialisasikan secara terintegrasi. Melalui wawancara awal tentang K3 dengan petugas kesehatan yang berprofesi sebagai bidan desa, diperoleh beberapa fakta yang menggambarkan kebutuhan akan penyelenggaraan pelatihan K3 dimana 1) adanya faktor penyebab lainnya yang juga mempengaruhi tertundanya usaha promotif Puskesmas yaitu masih rendahnya pengetahuan tentang prinsip K3 pertanian yang dimiliki oleh petugas kesehatan yang wilayah kerjanya di Desa Antapan, 2) Adanya prevalensi Infeksi Saluran Pernafasan Atas pada pasien yang bekerja sebagai petani, dan 3) Kejadian kasus keracunan pestisida akut pernah ditangani yang dialami oleh pasien yang merupakan petani di Desa Antapan. Berdasarkan hasil observasi dan wawancara lainnya dengan masyarakat desa Antapan yang mayoritas bekerja sebagai petani maka ditemukan beberapa hal berikut ini yaitu 1) Petani mengalami keluhan tentang kondisi kesehatan utamanya gangguan saluran pernafasan dengan beberapa diantaranya mengalami gangguan pencernaan, 2) Petani kurang memahami tentang K3 dikarenakan rendahnya pengetahuan mereka serta belum adanya pembinaan K3 bagi mereka yang mereka jadikan sebuah kebutuhan karena adanya kasus keracunan yang pernah terjadi pada petani di wilayah desa Antapan tersebut. Pelatiahn K3 diberikan dalam metode ceramah, diskusi dan praktek pendampingan berlangsung sangat efektif dengan tercapainya tujuan pengabdian berupa peningkatan wawasan. Pada saat dilaksanakan monitoring evaluasi setelah 2 minggu pelaksanaan, masyarakat petani desa Antapan telah menerapkan prinsip K3 pada keseharian mereka melakukan pekerjaannya.
\end{abstract}

Kata kunci : Kesehatan dan Keselamatn Kerja (K3), Petani Desa Antapan

\begin{abstract}
Farmers are the largest working group as occupation in Indonesia. Agriculture and plantations can be considered as a closed society, so that health efforts must be adjusted to the properties of such communities, in the sense of organizing themselves and for their own needs. Occupational Health and Safet ar in Indonesia known as Kesehatan dan Keselamatn Kerja (K3) proper behavior in the use of pesticides is very important for prevention of poisoning, so that the behavior of pesticide users K3 farmers need to be socialized in an integrated manner. Through an initial interview about K3 with health workers who work as midwives, obtained some facts that illustrate the need for organizing training K3 where 1) the existence of other factors that also affect the delay in efforts promotive health center is still lack of knowledge about the principle of $\mathrm{K} 3$ farm owned by officer health whose jurisdiction the village Antapan, 2) The prevalence of Upper Respiratory Tract Infections in patients who work as farmers, and 3) incident cases of acute pesticide poisoning ever dealt with that experienced by patients who are farmers in the village Antapan. Based on observations and interviews with other villagers Antapan majority worked as a farmer, found the following points: 1) Farmers have complaints about the health condition of the main respiratory disorders with some of them experiencing indigestion, 2) Farmers have less conception of $\mathrm{K} 3$ due to their lack of knowledge and the lack of guidance $\mathrm{K} 3$ for those whom they made a requirement because of the poisoning cases that have occurred on farmers in the village area Antapan. K3 agriculture training given in a lecture, discussion and practice of mentoring takes place very effectively with the achievement of the devotion of increased insight. At the time of monitoring and evaluation carried out after 2 weeks of
\end{abstract}


implementation, Antapan rural farming communities have applied the principle of $\mathrm{K} 3$ in their daily lives to do his occupational activity.

Keywords: Occupational health and safety, agriculture, Antapan Village

\section{PENDAHULUAN}

Petani merupakan kelompok kerja terbesar di Indonesia. Meski ada kecenderungan semakin menurun, angkatan kerja yang bekerja di sektor pertanian masih berjumlah 42 juta orang atau sekitar $40 \%$ dari angkatan kerja. Banyak wilayah kabupaten di Indonesia yang mengandalkan pertanian, termasuk perkebunan sebagai sumber penghasilan daerah. Utamanya di Provinsi Bali, pariwisata dan pertanian menjadi dua lumbung penghasil pendapatan daerah.. Dalam perspektif kesehatan dan keselamatan kerja penerapan teknologi pertanian adalah memiliki sisi dependent health risk. Oleh karena itu ketika terjadi sebuah pemilihan sebuah teknologi, secara implisit akan terjadi perubahan faktor resiko kesehatan. Penerapan teknologi baru di pertanian memerlukan adaptasi sekaligus keterampilan. Adaptasi yang dialami tentunya adalah adaptasi terhadap interaksi petani dan lingkungan serta kondisi kesehatannya. Sebagai contohnya teknologi mencangkul kini digantikan dengan traktor, hal ini jelas mengubah faktor resiko kesehatan dan keselamatan kerja yang dihadapi oleh petani. Demikian pula dengan penggunaan pestisida, seperti indikasi penggunaan dalam upaya pemberantasan hama, takaran penggunaan, teknik penyemprotan, dan lain-lain. Ironisnya teknologi baru ini memiliki potensi bahaya kesehatan akut dan kronik. Pestisida merupakan bahan kimia untuk membunuh hama tanaman. Apabila tidak tepat dalam penggunaannya, bisa menyebabkan keracunan. Perilaku K3 yang tepat dalam penggunaan pestisida sangat penting sebagai upaya pencegahan keracunan, sehingga perilaku K3 petani pengguna pestisida perlu disosialisasikan secara terintegrasi. Pertanian dan perkebunan dapat dianggap sebagai satu masyarakat tertutup, sehingga usaha-usaha kesehatan pun harus disesuaikan dengan sifat-sifat masyarakat demikian, dalam arti menyelenggarakan sendiri dan untuk kebutuhan sendiri. Dalam hal ini sesuai pula dengan luas lahan pertanian atau perkebunan yang sudah sepatutnya ada usaha-usaha meliputi bidang preventif dan kuratif, baik mengenai penyakit umum, kecelakaan kerja, dan penyakit akibat kerja. Puskesmas Pembantu Desa Antapan sebagai fasilitas kesehatan primer yang sedianya memberikan layanan kesehatan promotif, preventif dan kuratif sederhana. Program Kegiatan Puskesmas Pembantu Desa Antapan yang telah dilaksanakan selama ini berupa tindakan preventif dan kuratif sederhana yang rutin setiap satu bulan sekali melalui kegiatan posyandu. Upaya promotif diakui belum dapat dilaksanakan oleh petugas dikarenakan keterbatasan jumlah petugas serta ketersediaan waktu. Melalui wawancara awal tentang K3 dengan petugas kesehatan yang berprofesi sebagai bidan desa, diperoleh beberapa fakta yang menggambarkan kebutuhan akan penyelenggaraan pelatihan K3 dimana 1) adanya faktor penyebab lainnya yang juga mempengaruhi tertundanya usaha promotif Puskesmas yaitu masih rendahnya pengetahuan tentang prinsip K3 pertanian yang dimiliki oleh petugas kesehatan yang wilayah kerjanya di Desa Antapan, 2) Adanya prevalensi Infeksi Saluran Pernafasan Atas pada pasien yang bekerja sebagai petani, dan 3) Kejadian kasus keracunan pestisida akut pernah ditangani yang dialami oleh pasien yang merupakan petani di Desa Antapan. Berdasarkan hasil observasi dan wawancara lainnya dengan masyarakat desa Antapan yang mayoritas bekerja sebagai petani maka ditemukan beberapa hal berikut ini yaitu 1) Petani mengalami keluhan tentang kondisi kesehatan utamanya gangguan saluran pernafasan dengan beberapa diantaranya mengalami gangguan pencernaan, 2) Petani kurang memahami tentang K3 dikarenakan rendahnya pengetahuan mereka serta 
belum adanya pembinaan K3 bagi mereka yang mereka jadikan sebuah kebutuhan karena adanya kasus keracunan yang pernah terjadi pada petani di wilayah desa Antapan tersebut.

\section{SUMBER INSPIRASI}

Desa Antapan di Kecamatan Baturiti memiliki penduduk 1.065 Kepala Keluarga (KK) yang mayoritas pekerjaan sebagai petani $(745 \mathrm{KK})$ yang tersebar di 6 (enam) banjar (dusun) yaitu Banjar Anatapan, Banjar Talampati, Banjar Tohjiwa, Banjar Mayungan Anyar, Banjar Mayungan Let, dan Banjar Gelogor. Lahan pertanian didominasi dengan penanaman tanaman sayur dan buah seperti strawberry, tomat, kubis, sawi putih, wortel dan paprika. Data awal yang kami peroleh dari pencatatan prevalensi kasus di poliklinik Puskesmas Pembantu Desa Antapan, masyarakat usia produktif menyumbangkan 35-50 kasus Infeksi Saluran Pernafasan Bagian Atas (ISPA) setiap bulannya. Dari jumlah kasus tersebut, sekitar $80 \%$ pasien bekerja sebagai petani. Kasus keracunan (intoksikasi) akut pernah dirujuk oleh puskesmas pembantu di desa Antapan ini yang dialami oleh seorang petani sehabis melakukan pembasmian hama dengan penyemprotan pestisida. Jumlah kasus intoksikasi pestisida setiap tahun yang tercatat di puskesmas sebanyak 3-5 kasus. Catatan kasus ISPA dan intoksikasi ini tentunya memerlukan perhatian khusus berkaitan dengan penyebabnya. Faktor predisposisi timbulnya kasus ISPA pada penduduk desa Antapan adalah tindakan berisiko tinggi mereka yang akrab dengan pestisida dalam melakukan pekerjaan mereka dalam bercocok tanam. Pestisida sebagai bahan kimia yang telah diketahui memiliki efek terhadap kesehatan baik akut maupun kronis bagi seseorang yang seringkali menerima paparan pestisida. Pengorganisasian petani sayur di desa Antapan yang belum terangkum dalam sebuah wadah kelompok tani menjadi salah satu fenomena yang dirasakan pentani di desa Antapan sebagai faktor penyulit capaian Dinas Pertanian maupun Dinas Kesehatan dalam upaya promotif dan preventif Keselamatan dan
Kesehatan Kerja (K3) bagi petani. Petani desa Antapan selama ini berkembang sebagai petani yang mandiri dengan bekal pengetahuan sangat minimal tentang $\mathrm{K} 3$. Penuturan dari pihak aparat desa dan petugas Puskesmas setempat menggambarkan penerapan teknologi pertanian sederhana seperti penggunaan traktor dan pemanfaatan pestisida belum dibarengi dengan pengetahuan tentang K3 yang bermuara pada tindakan beresiko tinggi yang berdampak pada kondisi kesehatan petani di desa Antapan. Berdasarkan observasi awal setelah mengkaji hasil wawancara dengan aparat desa, petugas kesehatan dan juga petani di desa Antapan, maka didapatkan perilaku yang tergolong tindakan beresiko tinggi yang terkait dengan lonjakan kasus ISPA dalam catatan kunjungan Puskesmas Pembantu di setiap bulannya. Perilaku yang kurang memperhatikan prinsip K3 dalam pemanfaatan pestisida salah satunya adalah minimalnya penggunaan Alat Pelindung Diri (APD). Berdasarkan observasi awal di lapangan, petani yang menggunakan APD hanya sebanyak $10 \%$ dari total petani yang bekerja. Penggunaan APD yang digunakan ternyata belum memenuhi syarat dalam prinsip K3. Petani di desa Antapan menyadari pengetahuan mereka tentang K3 dalam pekerjaan mereka bertani masih rendah sehingga petani di desa Antapan memerlukan adanya pelatihan untuk meningkatkan pengetahuan mereka tentang K3 serta keterampilan mengaplikasiskan pengethuan tersebut yang pada akhirnya nanti bermuara pada peningkatan status kesehatan mereka. Berdasarkan analisis permasalahan dan kebutuhan akan pemecahan dari masalah yang dihadapi oleh petani di desa Antapan tersebut maka diperlukan sebuah usaha untuk memenuhi permintaan petani di desa tersebut untuk diadakannya sebuah usaha peningkatan pengetahuan dan keterampilan tentang K3. Upaya K3 yang diberikan nantinya dalam pelatihan seperti bagaimana menggunakan pestisida secara aman, bagaimana menggunakan bahan kimia berbahaya secara benar agar tidak membahayakan diri petani dan lingkungannya serta upaya pencegahan 
dan pengobatan penyakit yang berkaitan dengan pekerjaannya.

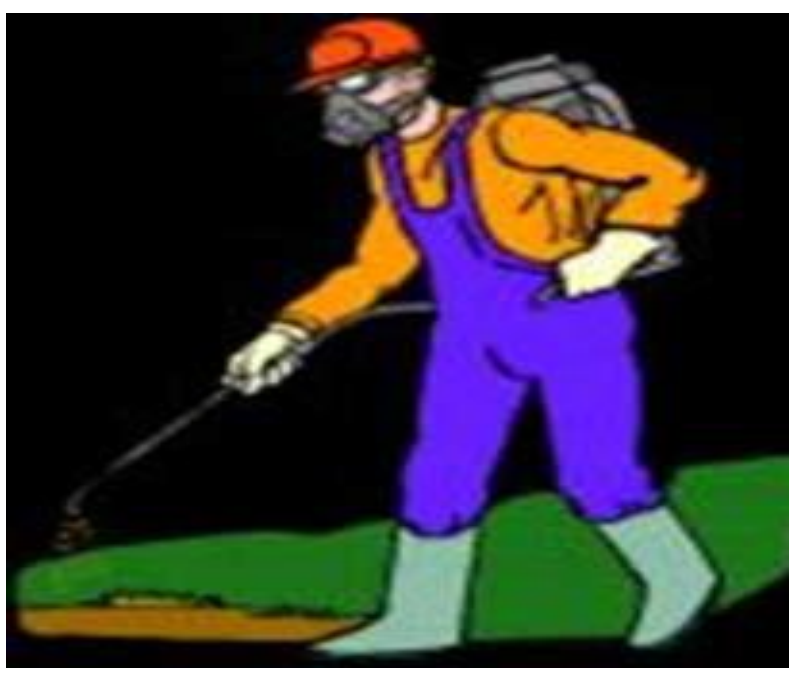

Gambar 01. Penggunaan APD Sesuai Prinsip K3 dalam Aktivitas Penyemprotan Pestisida (Sumber : Balai Hiperkes, 2010)

\section{METODE}

Metode yang digunakan dalam program P2M ini adalah pelatihan yang ditujukan kepada petugas kesehatan dan petani di desa Antapan. Dalam hal meningkatkan,pengetahuan petugas kesehatan dan petani maka metode pelatihan dipilih dibandingkan metode seminar. Hal ini dikarenakan informasi lebih mudah diserap dan diingat apabila materi diberikan ke dalam bentuk yang lebih nyata atau bentuk pengalaman dibandingkan hanya dalam bentuk lisan atau tulisan. Keterkaitan program P2M yang akan dilakukan dengan berbagai pihak yaitu Universitas Pendidikan Ganesha, Aparat Desa Antapan, Puskesmas Kecamatan Baturiti serta Dinas Kesehatan dan Dinas Pertanian Kabupaten Tabanan sebagaimana memang dalam permasalahan di bidang kesehatan umumnya diperlukan keterkaitan berbagai pihak.

Pelaksanaan pelatihan tentan Kesehatan dan Keselamatan Kerja dilaksanakan dengan metode pelatihan yang disambut antusias oleh seluruh peserta.

Metode pelaksanaan pelatihan berupa :

1. Penyampaian materi oleh narasumber yang kompeten di bidangnya.

Memberikan pengetahuan dasar tentang K3

2. Diskusi setelah penyampaian materi

3. Pendampingan oleh narasumber dan tim pelaksana (praktek menggunakan alat pelindung diri)

4. Evaluasi pendampingan dengan diskusi akhir untuk menatik simpulan kegiatan

\section{KARYA UTAMA}

Sasaran dari pelatihan ini adalah petugas kesehatan dan petani di wilayah desa Antapan yang seluruhnya berjumlah 50 orang. Petugas kesehatan di Puskesmas Pembantu merupakan petugas yang lebih sering kontak dan lebih dekat dengan petani dibandingkan dengan petugas kesehatan lainnya. Dengan kemantapan pengetahuan yang nantinya dimiliki diharapkan petugas kesehatan tidak hanya semata melakukan rutinitas kegiatan pelayanan kesehatan bagi pasien yang datang ke Puskesmas saja tetapi nantinya dalam program pendampingan dapat melaksanakan promosi dan pemyuluhan kesehatan tentang K3 kepada petani di wilayah desa Antapan. Meningkatnya pengetahuan petani melalui pelatihan ini sebagai peserta nantinya diharapkan dapat memberikan pengaruh besar bagi peningkatan kesadaran aplikasi prinsip K3 di wilayah Desa Antapan demi peningkatan status kesehatannya.

\section{ULASAN KARYA}

Pihak mitra menyambut kegiatan pelatihan ini dengan sangat antusias dan penuh rasa kekeluargaan. Kendala medan yang cukup terjal karena area desa berada di lereng bukit tidak menjadi hambatan bagi tim pelaksana dikarenakan petani serta aparat desa dan pihak puskesmas menyambut kami dengan sangat baik. Tempat pelaksanaan di balai pertemuan yang dekat dengan kandang dari kelompok tani di desa antapan yang telah sering menjuarai perlombaan tingkat provinsi. Namun di awal pelatihan, tingkat pengetahuan tentang kesehatan dan keselamatan kerja sangat rendah. Dan kemudian sangat berbangga tim pelaksana dan mitra dapat bersama 
memberikan peningkatan wawasan tentang kesehatan dan keselamatan kerja bagi petani di desa antapan.

\section{DAMPAK DAN MANFAAT KEGIATAN}

Hasil pelaksanaan program $\mathrm{P} 2 \mathrm{M}$ ini diharapkan nantinya dapat digunakan sebagai masukan kepada Dinas Kesehatan dan Puskesmas Kecamatan Baturiti yang dapat digunakan sebagai bahan pertimbangan dalam pelaksanaan program perbaikan status kesehatan masyarakat di desa Antapan khususnya serta di wilayah lainnya di Kabupaten Tabanan yang mayoritas bekerja di bidang pertanian dan perkebunan sehingga dapat dilaksanakan pemantapan program melalui usaha peningkatan pengetahuan petugas kesehatan dan kader tentang prinsip K3 sebagai upaya peningkatan status kesehatan masyarakat. Dengan kemampuan dalam memberikan Komunikasi, Informasi serta Edukasi yang prima maka petugas kesehatan dan kader nantinya akan dapat memberikan kegiatan promosi dan penyuluhan kesehatan yang tepat guna mendukung program promotif dan preventif terkait K3. Melalui promosi dan penyuluhan kesehatan yang baik diharapkan pengetahuan masyarakat petani khususnya tentang K3 menjadi lebih baik yang tentunya akan meningkatkan status kesehatannya.

\section{KESIMPULAN}

Kegiatan pengabdian dalam bentuk pelatihan ini telah berhasil mencapai tujuannya yaitu meningkatkan pengetahuan petani tentang peran penting penerapan prinsip $\mathrm{K} 3$ bagi kesehatan petani di desa Antapan , Kecamatan Baturiti dan menekankan pentingnya nilai status kesehatan manusia yang tidak dapat digantikan oleh harta benda maupun uang. Melalui pelatihan dengan mengusung slogan "Sehat sayurku, sehat petaniku" dalam tehnik demonstrasi tentang pemakaian Alat Pelindung Diri (APD) yang lengkap dan benar maka faktor enabling yaitu ketersediaan dan kemudahan pemakaian APD akan dapat diterima dengan baik oleh petani di desa Antapan, Kecamatan Baturiti.

\section{DAFTAR PUSTAKA}

Cascio, W.F. 1998. Managing Human Resources - Productivity Quality of Work Life, Profits. Edisi ke-5. McGraw Hill, Amerika Serikat.

Darmanto, R. 1999. Kesehatan Kerja di Perusahaan. PT Gramedia Pustaka Utama, Jakarta.

Santoso, G. 2004. Manajemen Keselamatan dan Kesehatan Kerja. Prestasi Pustaka, Jakarta.

Suardi, R. 2005. Sistem Manajemen Keselamatan dan Kesehatan Kerja. Penerbit PPM, Jakarta.

Sugeng, A.M., dkk. 2005. Bunga Rampai Hiperkes \& KK Edisi Kedua. Badan Penerbit Universitas Diponegoro,Semarang.

Jung DY, Kim HC, Leem JH, Park SG, Lee $\mathrm{DH}$, Lee SJ dan Kim GW, 2011. Estimatedoccupational injury rate and work related factors based on data from the fourth Korea National Health and Nutrition Examination Survey. Korean Journal Occupational Environment Medicine , 23(2):149-163.

Chae $\mathrm{H}$, Kyungdoo M, Youn K, Jinwoo P3, Kyungran K1, Hyocher $\mathrm{K} 1$ and Kyungsuk L, 2014. Estimated rate of agricultural injury: the Korean Farmers' Occupational Disease and Injury Survey Chae et al. Annals of Occupational and Environmental Medicine , 26:8 